\title{
Setup of tools and dataset selection for MBL investigation over a coastal Mediterranean site - preliminary results
}

\author{
L. Velea ${ }^{1}$, G. L. Liberti ${ }^{1}$, A. M. Sempreviva ${ }^{2,3}$, and C. Transerici $^{1}$ \\ ${ }^{1}$ ISAC-CNR, Via Fosso del Cavaliere, 100, Rome, 00133, Italy \\ ${ }^{2}$ ISAC-CNR, c/o CRATI Zona Industriale area ex SIR, 88046, Lamezia Terme, Italy \\ ${ }^{3}$ Ris $\varnothing$-DTU, Frederiksborgvej 399, 4000 Roskilde, Denmark
}

Received: 2 January 2008 - Revised: 30 October 2009 - Accepted: 3 November 2009 - Published: 24 November 2009

\begin{abstract}
We propose the height $z_{i}$ of the inversion in the vertical profile of potential temperature, on the top of a mixed layer or of a residual layer as a relevant parameter for retrieving information related to water vapour in the lower layers of the atmosphere, from currently available operational satellites information. We estimated $z_{i}$ using an algorithm where a set of threshold values in the vertical gradients of potential temperature are used to analyse the available profiles in order to find relevant inversions. Thresholds are derived from the subjective analysis of a set of high vertical resolution soundings from the coastal site of the Italian Meteorological Service of Pratica di Mare (WMO \#16245, lat. $41.66^{\circ} \mathrm{N}$, lon. $12.45^{\circ} \mathrm{E}$ ).

The sensitivity of the method to vertical sampling is tested comparing results obtained by applying the method to two sets of about 6500 raw and sampled radiosoundings during the period 2002-2008. Differences in average seasonal and six-hourly values of $z_{i}$ from the two datasets are found within the range 5-10\%. The method was then applied to a larger set of soundings from coastal and continental Mediterranean sites collected in a standard archive. It was found that mean summer values of $z_{i}$ at coastal sites are lower than in winter, conversely to continental sites.

Furthermore, values of $z_{i}$ found using the proposed algorithm show a systematically higher inversion if compared to height found using the Richardson Number method, although there are cases when both identify the inversion at the same height.
\end{abstract}

\section{Introduction}

Retrieval of Atmospheric Boundary Layer (ABL) properties from operational satellite passive remote sensing observations is a challenging issue mostly because of the difficulties in quantifying the partition between surface and ABL contributions within the measured signal. Operational products relative to water vapour characteristics, e.g. vertical profile, Total Precipitable Water Vapour (TPWV), precipitable water vapour integrated over given layers (LPWV), based on different instruments (SSM/I (Special Sensor Microwave Imager), ATOVS (Advanced TIROS Operational Vertical Sounder), and SEVIRI (Spinning Enhanced Visible and Infrared Im-

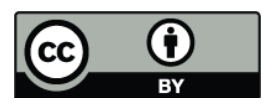

Correspondence to: L. Velea (liliana.velea@artov.isac.cnr.it) ager)) are available at various time and space scales. However, information content of currently available satellite observations, particularly IR pseudo-sounding radiometers as SEVIRI, has not been yet fully investigated and thus exploited.

This study is aimed to investigate, using radiosoundings, the possibility to define a parameter, somehow related to the distribution of water vapour in the lowest layers of the atmosphere, which can be retrieved from currently available satellite passive remote sensing observations. In this frame, we propose the height $z_{i}$ of the base of the inversion capping a mixed layer or a residual layer, estimated using an algorithm that identifies the inversion in each vertical profile of potential temperature $(\Theta)$ as such parameter. We focus offshore areas where the almost constant surface emissivity of the sea surface leads to fewer problems in interpreting remote sensing observations. 
We assume that information relative to air-sea interaction may be retrieved from the available satellite measurements using $z_{i}$. In particular, the mixing height may be used into a relationship for partitioning the TPWV in the entire column and in the mixed layer contribution; therefore this relation, together with satellite information about TPWV in the entire column, may be used to estimate TPWV in the mixed layer, with the advantage of providing spatial coverage otherwise hardly accessible for such measurements. Investigations related to the detection and characterization of temperature inversions in the boundary layer from passive infrared radiometry has been examined by several authors (e.g. Liu and Key, 2003; Fetzer et al., 2004; Hyvarinen and Rantamaki, 2004; Liu et al., 2006).

High resolution radiosoundings provide detailed vertical distribution of atmospheric variables (e.g. temperature, wind) that allow estimating the mixing height. However, there are only sparse datasets of such measurements over sea areas. Homogeneous and quality controlled datasets for characterizing Marine Atmospheric Boundary Layers (MABL) suitable for our study are typically linked to experiments (e.g. Tropical Ocean Global Atmosphere Coupled Ocean Atmosphere Response Experiment (TOGA COARE) (Webster and Lukas, 1992), Flux, Etat de la mer, et Télédétection en Condition de Fetch variable (FETCH) (Hauser et al., 2003); therefore they are limited both in space and time although in North Europe, long-term campaigns with high resolution radio soundings are available i.e. the Danish Havn 90 (Sempreviva and Gryning, 2000), Östergansholm, Sweden (Gryning and Batchvarova, 2002; Johansonn et al., 2005). Nevertheless, for a relatively large number of coastal sites, pluridecadal time series of radiosoundings are easily available through quality controlled archives, but representativity for marine conditions must still be investigated.

Here, we develop a method for retrieving the height of the top of the ABL in convective and residual layers and we test it on a set of high resolution soundings available for a limited period (2002-2008) at the World Meteorological Organization (WMO) coastal Mediterranean site of Pratica di Mare in Italy. This reference dataset contains about 6500 soundings at the original $10 \mathrm{~s}$ sampling frequency. Statistics in terms of seasonal and diurnal variation of $z_{i}$ obtained from such dataset are compared with those obtained from the same set of soundings but with the low resolution vertical sampling available from the Integrated Global Radiosonde Archive (IGRA) (Durre et al., 2006), in order to evaluate the possible loss of information. The robustness of the methodology and the results obtained from such comparison have been then tested performing a similar analysis on a longer time series and on other radiosoundings from coastal and continental sites for the same period.

\section{Data and methods}

The radiosounding station of Pratica di Mare (WMO \#16245) $\left(41.66^{\circ} \mathrm{N}, 12.45^{\circ} \mathrm{E}\right)$ is located at about $3 \mathrm{~km}$ from the coast of the Tyrrhenian Sea and at a nominal elevation of 35 a.s.l. east of the town of Rome. The original sampling dataset (HIRES) is available for the period 2002-2008 and consists in raw data from standard radiosonde measurements routinely performed up to 4 times per day by the Italian Meteorological Service, with a sampling frequency of $10 \mathrm{~s}$, corresponding to a vertical resolution of roughly $35 \mathrm{~m}$. The IGRA dataset consists of archived radiosonde and pilot balloon observations at over 1500 globally distributed stations, available at standard, surface, tropopause and significant pressure levels. Data from Pratica di Mare are available for the period 1987-2008. The entire database is freely accessible at http://www.ncdc.noaa.gov/oa/climate/igra/index.php. Here, we considered the IGRA dataset of Pratica di Mare for two periods: we denoted as LOWRES the dataset for the period 2002-2008 when also the HIRES are available and as LOWRESall the entire available period.

We produced a working dataset for the period 2002-2008 containing only data that fulfill the following conditions:

- Both HIRES and LOWRES are available and the number of valid levels in the vertical temperature profile of the HIRES and LOWRES dataset to be at least 20 and 5 levels respectively;

- The height of last valid level to be at least $3000 \mathrm{~m}$ (this being assumed as the maximum allowed/possible height of mixed layer in the Mediterranean Region); and

- Availability of valid relative humidity (RH) profiles up to at least $3000 \mathrm{~m}$. This condition ensures that other methods for mixing height estimation (e.g. analysis of virtual potential temperature profile, analysis of vertical gradient of water vapour mixing ratio) may be applied, as a cross-check of the proposed detection algorithm.

Valid soundings have been grouped according to season (winter: December, January and February (DJF); spring: March, April and May (MAM); summer: June, July, August (JJA) and autumn: September, October and November (SON)) and time of launching, as shown in Table 1.

The proposed algorithm for estimating the height of the inversion, was finally applied, with the same set of thresholds, to the complete sampled dataset (LOWRESall) available at Pratica di Mare for the period 1987-2008 (Table 1 in parenthesis) and to five additional datasets of vertical profiles at Italian sites containing long-term time series of 4 daily measurements. We chose three coastal Mediterranean stations i.e. Trapani (TRA, WMO\#16429), Brindisi (BRI, WMO\#16320) and Cagliari (CAG, WMO\#16560) and two continental stations i.e. Milano (MIL, WMO\#16080) and Udine (UDI, WMO\#16044). 
Table 1. Number of soundings used for each season and each launching time, for the period June 2002-August 2008 available at Pratica di Mare. The number of sounding used for each season and each launching time from the IGRA database for the entire period are in parenthesis.

\begin{tabular}{ccccc}
\hline & $00: 00$ & $06: 00$ & $12: 00$ & $18: 00$ \\
\hline DJF & $486(1797)$ & $346(1342)$ & $503(1806)$ & $228(1236)$ \\
MAM & $483(1879)$ & $321(1482)$ & $490(1838)$ & $152(1305)$ \\
JJA & $508(1889)$ & $343(1376)$ & $526(1880)$ & $231(1270)$ \\
SON & $460(1823)$ & $247(1342)$ & $443(1779)$ & $243(1321)$ \\
\hline
\end{tabular}

\section{Methodology for estimating inversion height}

Several procedures to estimate the height of the inversion above a mixed layer or residual layer are described in the literature. The advanced parcel method and the evaluation of the gradient of the mixing ratio of water vapour seems to be most appropriate (Seibert et al., 2000; De Tomasi and Perrone, 2006) for convective and near neutral conditions; in stable conditions approaches based on the Richardson number and on the low level wind profile are more suitable (Joffre et al., 2001). In both stable and unstable cases, the detection of a critical inversion in the temperature profile, located at the top of the mixing layer, renders a mixing height estimate (Heffter, 1980; Dayan et al., 1996).

In this analysis, we developed and used a modified version of the temperature-inversion method, as it requires only temperature measurements that are more reliable and usually available. The method is based on analysis of the $\Theta$ profile. We have considered as the surface layer (SL), the valid layer closest to $110 \mathrm{~m}$; the algorithm then searches $z_{i}$ by analysing $200 \mathrm{~m}$-thick sub-layers ( $\mathrm{SbL}$ ), included in a vertical range defined by the top of the SL and the maximum allowed PBL top $(3000 \mathrm{~m})$.

First step is to detect relatively large positive discontinuities within each candidate sub-layer, where the condition is:

$\Delta \Theta>0.5 \mathrm{~K}$

For each sub-layer, where this condition is fulfilled, the vertical gradient of $\Theta$ between the upper boundary of the sublayer and SL top is computed as an estimate of the mixing within the layer between the two levels. The searched inversion will be on the level with the largest vertical gradient of $\Theta$ between the considered level and the SL top that satisfy the following condition:

$\frac{\Delta \Theta}{\Delta z}<0.004 \mathrm{~K} / \mathrm{m}$

These thresholds were chosen based on visual check of results from a set of randomly selected cases from high resolution dataset, independently from season/time of the day and were applied also to low resolution soundings.
Table 2. Settings of sensitivity experiments for the detection algorithm.

\begin{tabular}{ccccc}
\hline & BL top $[\mathrm{m}]$ & SbL $[\mathrm{m}]$ & $\frac{\Delta \Theta}{\Delta z}\left[\mathrm{Km}^{-1}\right]$ & $\Delta \Theta[\mathrm{K}]$ \\
\hline exp1 & 3000 & 100 & 0.002 & 0.5 \\
exp2 & 3000 & 200 & 0.002 & 0.5 \\
exp3 & 3000 & 200 & 0.004 & 1.0 \\
ctrl & 3000 & 200 & 0.004 & 0.5 \\
\hline
\end{tabular}

Table 3. Number of cases, out of total number of soundings used (in \%), when an inversion was found using the proposed method, for datasets HIRES, LOWRES and LOWRESall.

\begin{tabular}{cccccl}
\hline Season & $00: 00$ & $06: 00$ & $12: 00$ & $18: 00$ & Dataset \\
\hline \multirow{3}{*}{ DJF } & 67.9 & 56.6 & 91.0 & 82.0 & HIRES \\
& 68.3 & 56.4 & 89.7 & 81.1 & LOWRES \\
& 59.3 & 46.5 & 87.0 & 77.9 & LOWRESall \\
\hline \multirow{3}{*}{ MAM } & 59.0 & 47.0 & 85.3 & 77.6 & HIRES \\
& 60.9 & 48.9 & 88.0 & 77.6 & LOWRES \\
& 57.2 & 46.7 & 89.4 & 81.2 & LOWRESall \\
\hline \multirow{3}{*}{ JJA } & 45.5 & 33.5 & 86.1 & 65.8 & HIRES \\
& 45.7 & 37.3 & 82.5 & 66.7 & LOWRES \\
& 41.2 & 33.4 & 86.8 & 72.8 & LOWRESall \\
\hline \multirow{3}{*}{ SON } & 65.4 & 49.4 & 91.4 & 88.0 & HIRES \\
& 62.6 & 51.4 & 94.4 & 79.4 & LOWRES \\
& 58.7 & 47.2 & 92.5 & 81.6 & LOWRESall \\
\hline
\end{tabular}

Sensitivity tests (Table 2) regarding the threshold values for some of the detection parameters, applied identically to both datasets, showed that in general LOWRES is sensitive especially to the magnitude of gradient in $\Theta$, while high resolution data is more sensitive than LOWRES with respect to all parameters, likely due to the finer structure which shows different features that may meet the threshold conditions. Overall, these results suggest that sets of threshold values tuned for each type of datasets would exploit better the available information.

It should be pointed out that, since the developed algorithm is able to estimate the height of the inversion only in the presence of a mixed layer or a residual layer, the statistics derived will be representative for such particular sub-set of BL conditions. In Fig. 1a, b, examples of success and failure of the method in determining $z_{i}$, for both HIRES and LOWRES datasets are shown. In Fig. 1a a case with nearly the same $z_{i}$ is presented; Fig. $1 \mathrm{~b}$ shows a case when values of $z_{i}$ found in LOWRES and HIRES soundings differ of about $200 \mathrm{~m}$. Table 3 shows the number of cases when the proposed algorithm was able to identify $z_{i}$ in each dataset. 

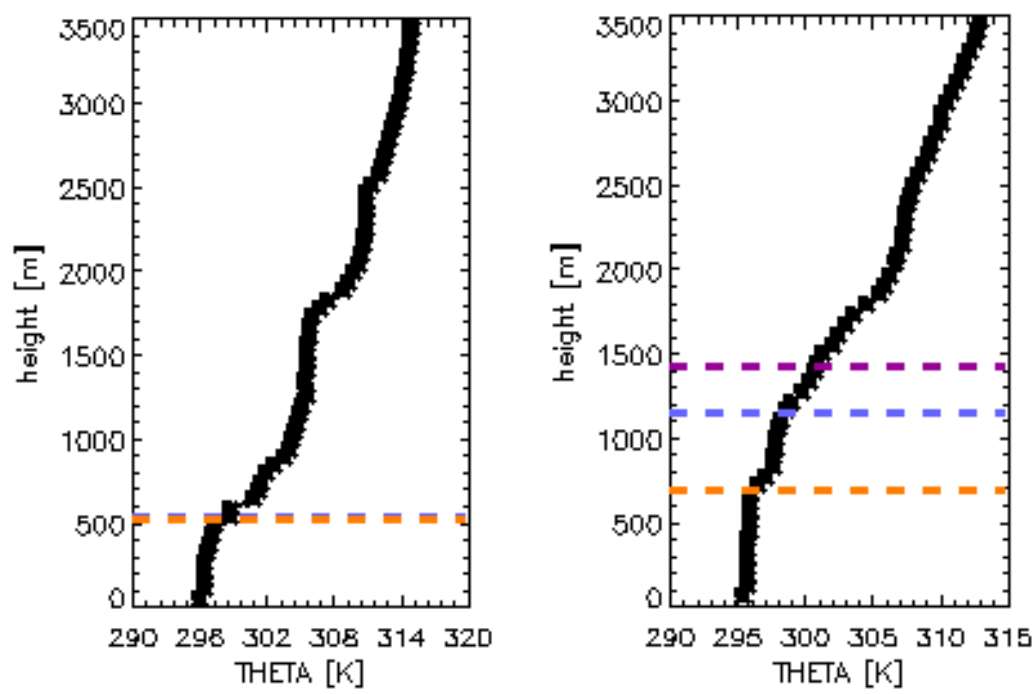

Figure 1. Examples of $z_{i}$ (horizontal lines) determined from LOWRES (blue line) and HIRES (pink line) datasets for (a) 29.06.2006, 23:00 UT; (b) 18.08.2007, 22:00 UT. Orange line marks the mixing height as found using RN method from HIRES dataset.
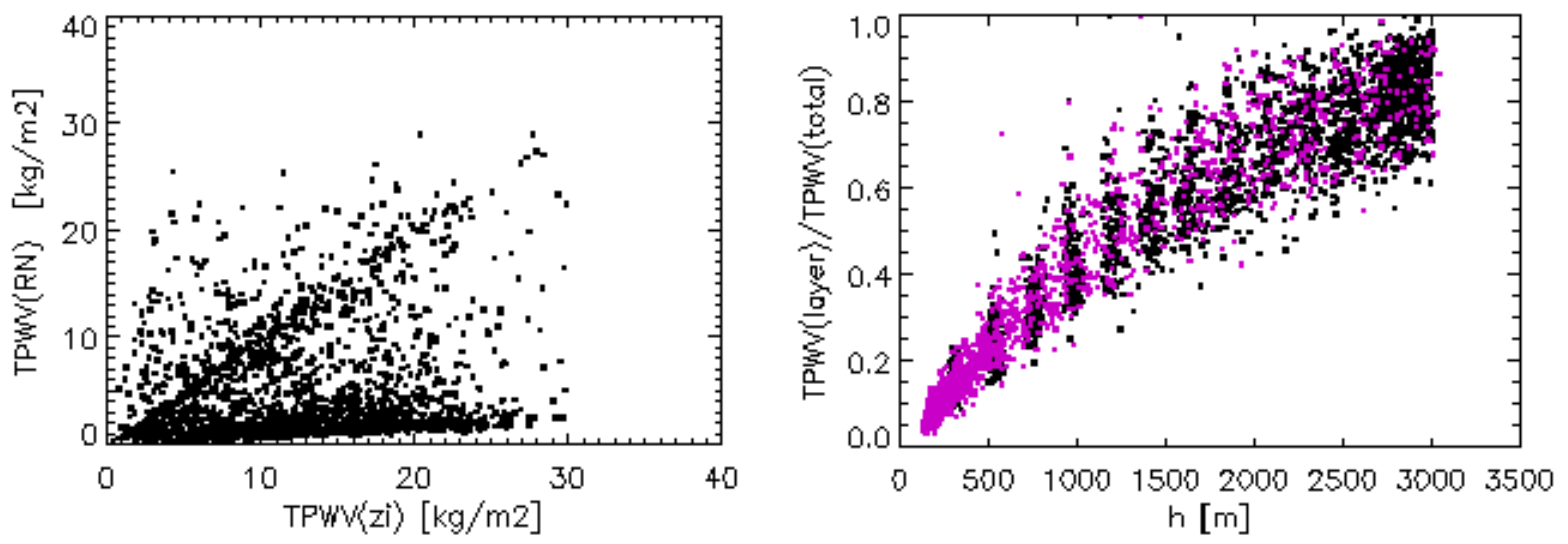

Figure 2. (a) Scatter plot of layered TPWV integrated from surface to $z_{i}\left(\mathrm{TPWV}\left(z_{i}\right)\right)$ and to RN height (TPWV(RN)); (b) Scatter plot of ratio between layered and total TPWV and the height of inversion as found with the algorithm proposed here (black dots) and the RN method (pink dots).

The comparison with estimated values of the mixing height by the Richardson Number method (RN) (Eresmaa et al., 2005; Joffre et al., 2001) shows a systematically lower inversion than the method proposed here, although there are cases when both methods identify the same inversion (Fig. 1a). On the other hand Fig. 2a shows the scatter plot of TPWV obtained by integrating radisounding observations between the surface and the level $z_{i}$ or the level derived with $\mathrm{RN}$ method. The distribution of the points shows two main clusters. One cluster lies around the 1:1 line and corresponds to cases where both algorithms agree. The second one shows that $z_{i}$ in most of the cases corresponds to a higher inversion that include about $80 \%$ of the TPWV (Fig. 2b), cases where probably the RN method did not work. These are profiles of more complex structure, where entrainment zone is not clearly confined and the first inversion that meets the criteria is found at height of the order of $2500-3000 \mathrm{~m}$. The presence of a secondary, higher inversion in the Marine ABL was first noticed at a location in the Danish Kattegat Sea by Sempreviva and Gryning (2000) who explained it as marking a residual layer or advection of a convective layer over land. Complex structure of vertical profiles of meteorological parameters was also observed in mountain valleys (Batchvarova et al., 2007). 

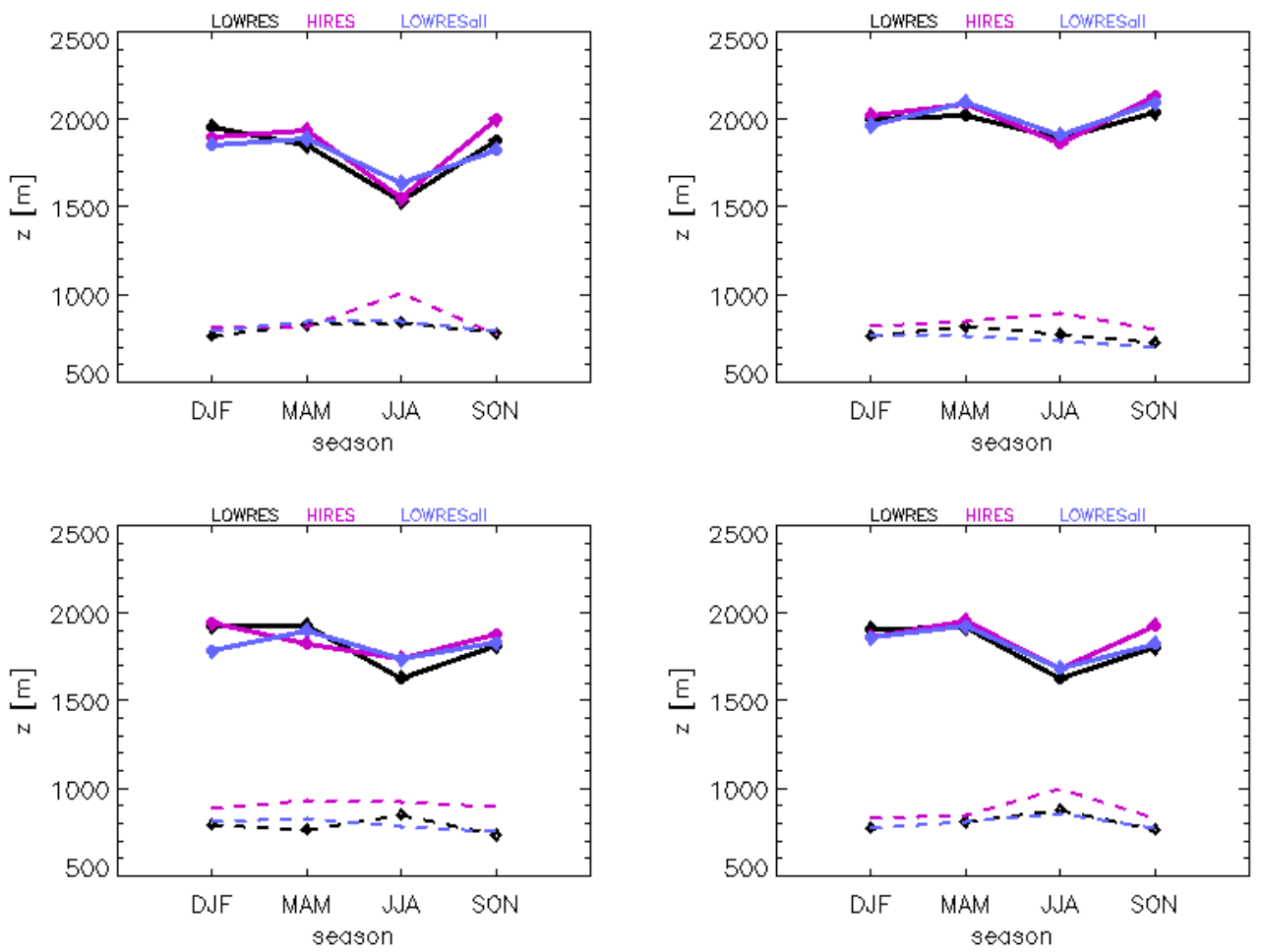

Figure 3. Seasonal average $z_{i}$ determined from HIRES (pink line), LOWRES (black line) and LOWRESall (blue line) for launching hours (from left to right, top-down): 06:00 UTC; 12:00 UTC; 18:00 UTC; 00:00 UTC. Dashed lines show the standard deviation of $z_{i}$.

\section{Results}

Seasonal averages of $z_{i}$ obtained at the Pratica di Mare station using HIRES and LOWRES datasets are plotted in Fig. 3, for each launching hour. The seasonal variation from HIRES and LOWRES datasets is similar and in general $z_{i}$ values are lower in summer than in the other seasons. Sempreviva and Gryning (2000) found that in summer $z_{i}$ is higher than in winter, at a site on a flat small island located in the middle of the Danish Kattegat Sea; however, Dayan et al. (1996, 1999); Martano, (2002); De Tomasi and Perrone (2006); and Sicard et al. (2006) found lower ABL during summer with respect to the other seasons in other studies at Mediterranean coastal sites. All authors explained low summer inversion by the advection of air from sea caused by sea breeze that limits the development of a full convective layer.

The dissimilarity between HIRES and LOWRES datasets estimates is more pronounced if the range of average values is considered. The inversion heights determined from LOWRES are overall lower than those from HIRES during night time, and slightly higher during day time, the relative difference being in the range $2-7 \%$ (Fig. 4).

The daily cycle, expressed in terms of the relative difference between average $z_{i}$ at reference hour 12:00 UTC and each other hour (Fig. 5), is comparable in both datasets at 00:00 UTC and 06:00 UTC; heights are generally larger at 12:00 UTC during summer (June-August), except for

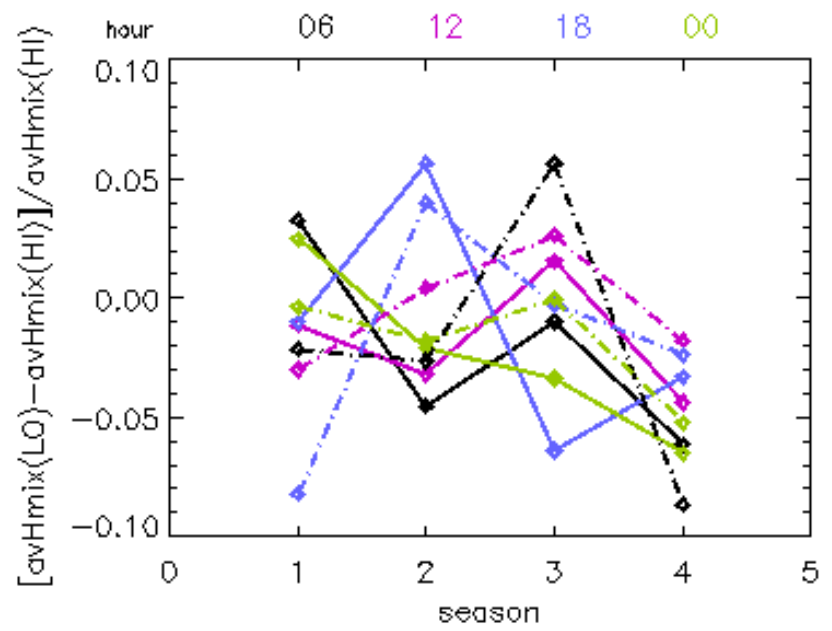

Figure 4. Relative difference between seasonal average $z_{i}$ derived from LOWRES and HIRES (solid lines) and LOWRESall and HIRES (dash-dotted lines), respectively. Colours indicate launching hours: 06:00 UTC (black), 12:00 UTC (pink), 18:00 UTC (blue) and 00:00 UTC (green).

18:00 UTC when in HIRES, larger heights at 12:00 UTC are found during spring instead of summer. The amplitudes of the daily cycle, generally in the range $3-18 \%$, are slightly larger in LOWRES. 

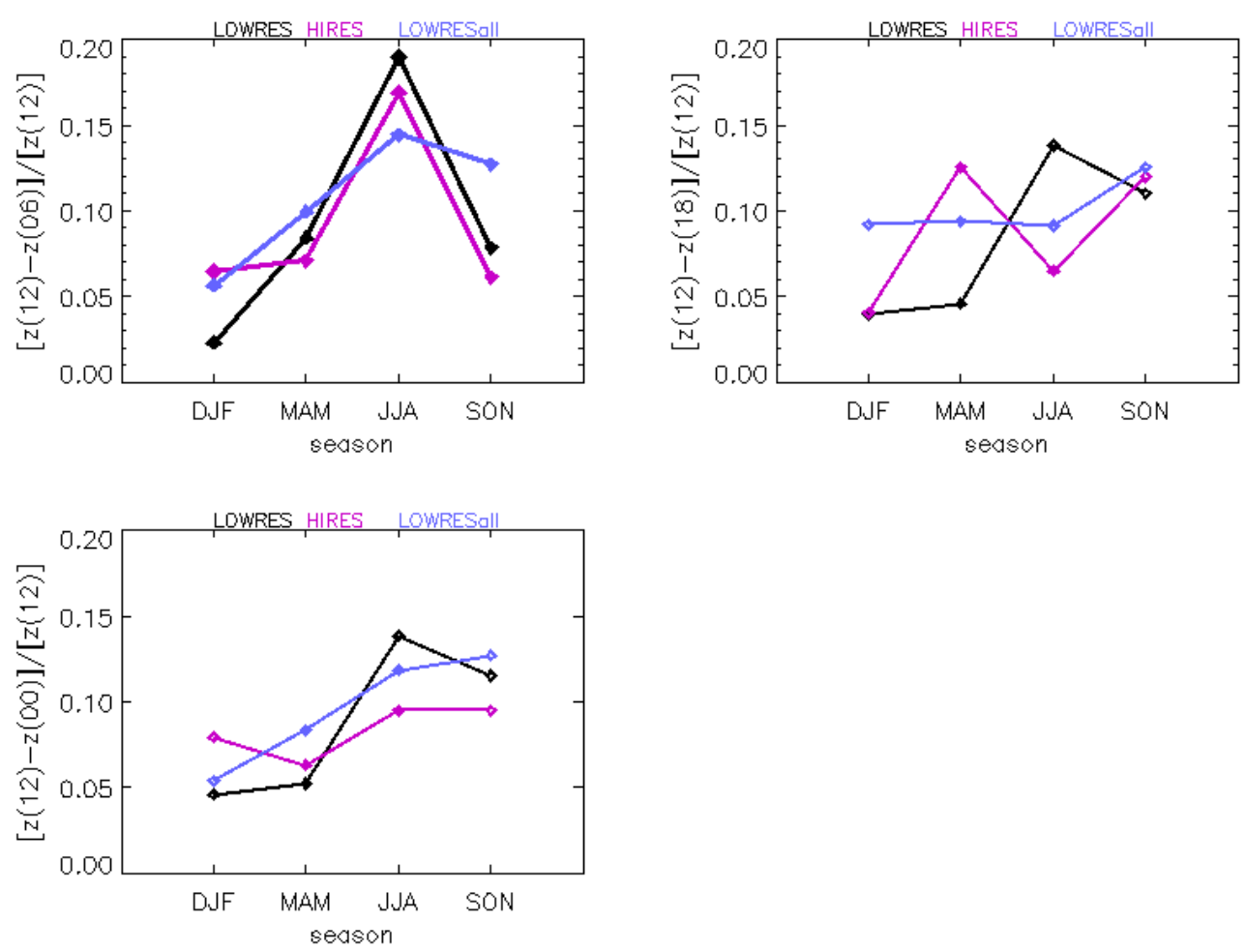

Figure 5. Daily cycle expressed as the relative difference between average $z_{i}$ at reference hour 12:00 UTC and each other hour, for HIRES (pink line), LOWRES (black line) and LOWRESall (blue line).

To check whether these differences are due to a poor number of analysed cases, the algorithm was also applied for the LOWRESall vertically sampled dataset available for Pratica di Mare. The comparison with HIRES shows a good agreement; the inversion heights are still lower than in HIRES at 00:00 UTC, but at 06:00 UTC they are higher of about 5\% and in general the daily cycle has a smoother variation over the year.

Then we investigated the features found at Pratica di Mare i.e. the lower inversion heights in summer, daily cycle of $z_{i}$ - considering five additional Mediterranean sites and applying the algorithm with the same set of thresholds to vertically sampled soundings available from the IGRA archive. We chose the Italian coastal stations of Trapani, Brindisi and Cagliari where we found similar characteristics with Pratica di Mare. The low $z_{i}$ in summer is less marked at Brindisi during night, and more pronounced at Trapani and Cagliari (Fig. 6). Also, all coastal stations exhibit a diurnal cycle, with largest amplitude at Cagliari (Fig. 7). In contrast, the continental stations of Milano and Udine show the expected seasonal behaviour i.e. a higher $z_{i}$ during summer than during winter.

In Fig. 8, we plot the radiosonde trajectories from the high resolution dataset at Pratica di Mare for each season. We note that, for the lowest $250 \mathrm{hPa}$, all lie mainly within around $15 \mathrm{~km}$ from the coast, and that most trajectories are towards inland during summer. Dayan et al. (1996, 1999) were the first to estimate a lower $z_{i}$ in summer with respect to winter arguing that this was due to the sea breeze circulation. From Figs. 6, 7 and 8, we can support the conclusion that, in coastal areas, the presence of the sea breeze induces an opposite annual cycle of the height of the inversion compared to continental sites. In this frame, coastal radiosoundings might be used for characterizing the marine boundary layer structure if a wind direction analysis is performed through the boundary layer choosing onshore flow considering the wind directions recorded at the ground station. A preliminary analysis of the HIRES dataset, with respect to nearsurface wind direction, showed that the volume of data available in cases of onshore and offshore wind would be drastically reduced, especially for the latter class, compared to the entire dataset (Table 4). However, the use of vertically sampled data, available for much longer period of times, may lead to more significant datasets for the two classes of wind regime. How and in which case coastal stations radiosounding might represent open-sea areas will be further explored, e.g. by comparing data from coastal stations, classified according to near-surface wind regimes, with data collected in open-sea areas, e.g. ASAP (Automated Shipboard Aerological Programme). 

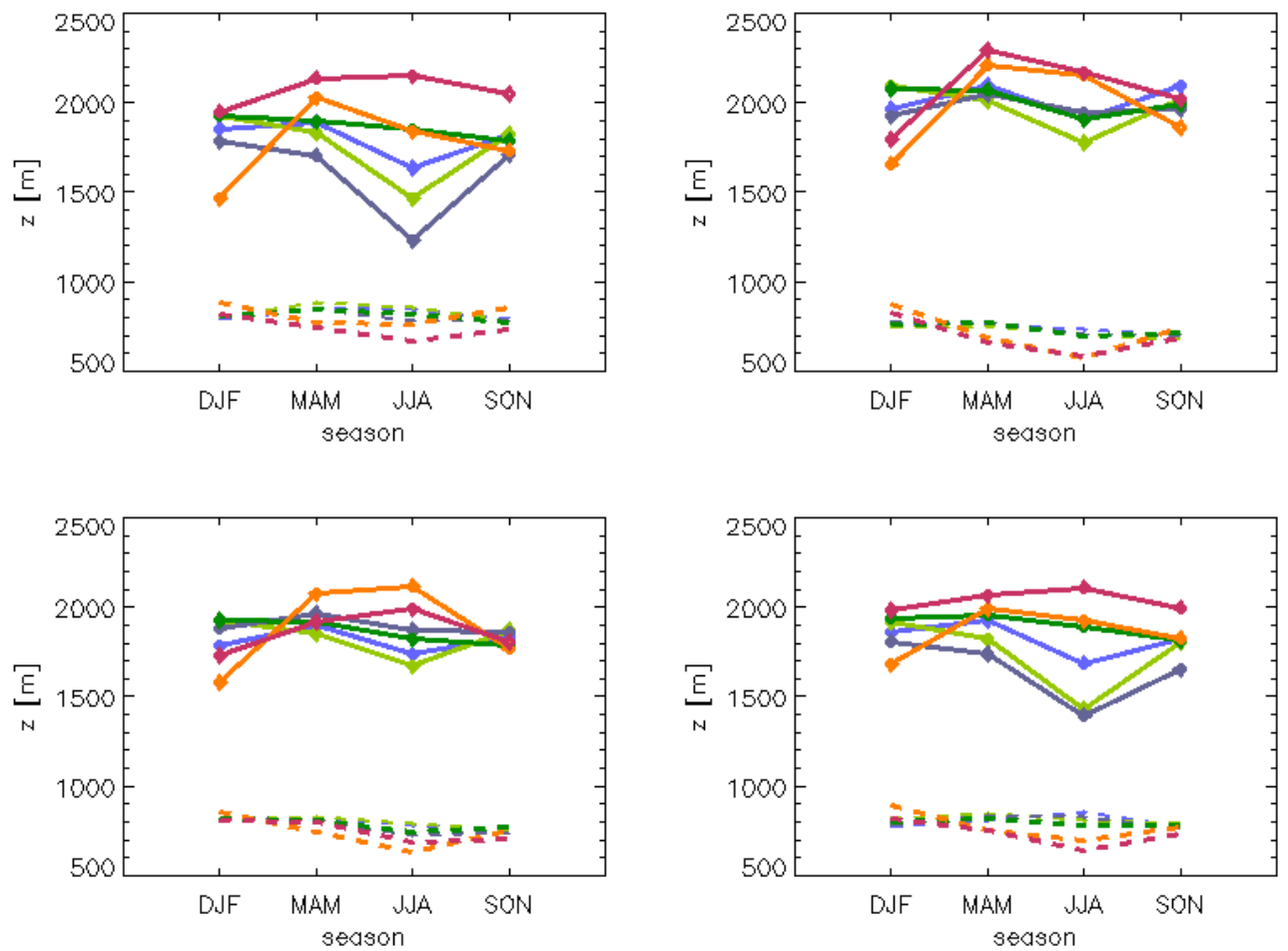

Figure 6. Seasonal average $z_{i}$ for launching hours (from left to right, top-down): 06:00 UTC; 12:00 UTC; 18:00 UTC; 00:00 UTC determined from HIRES (pink line), LOWRES (black line) and LOWRESall (blue line) at Pratica di Mare, and from vertically sampled soundings for Brindisi (dark green line), Trapani (light green line), Cagliari (dark blue line), Milano (orange line), and Udine (dark red line). Dashed lines show the standard deviation of $z_{i}$.
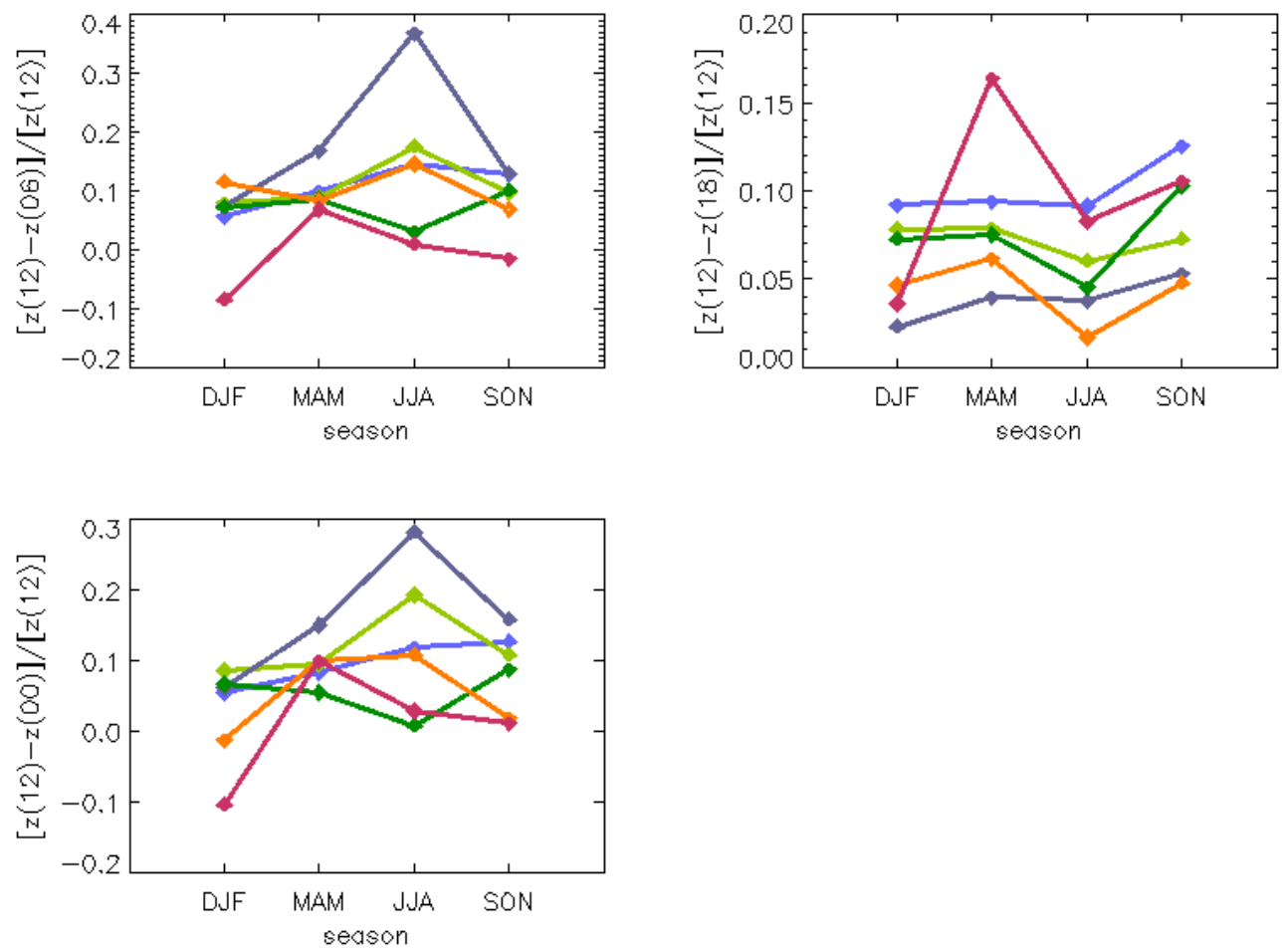

Figure 7. Daily cycle expressed as the relative difference between average $z_{i}$ at reference hour 12:00 UTC and each other hour, for $z_{i}$ determined from HIRES (pink line), LOWRES (black line) and LOWRESall (blue line) at Pratica di Mare, and from vertically sampled soundings for Brindisi (dark green line), Trapani (light green line), Cagliari (dark blue line), Milano (orange line), and Udine (red line). 
DJF

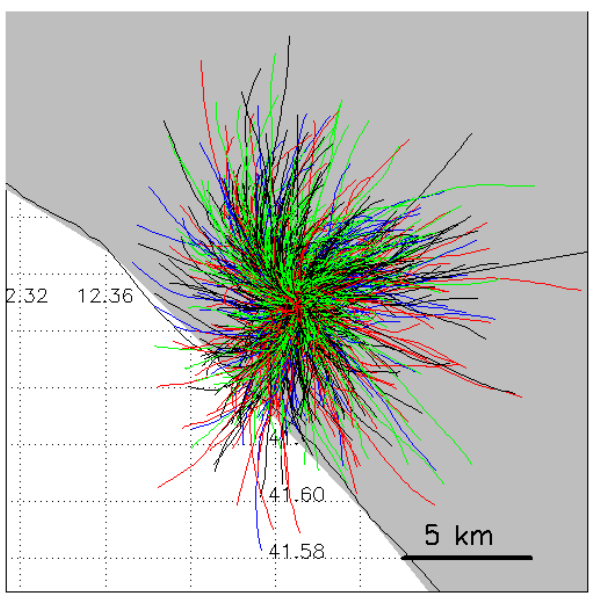

JJA

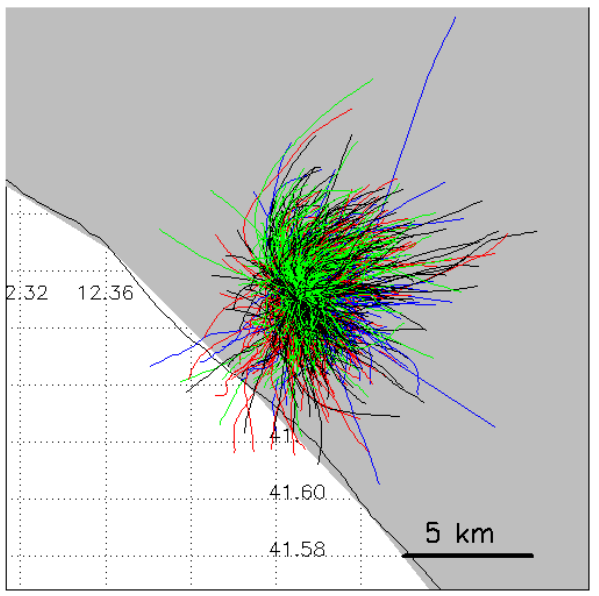

MAM

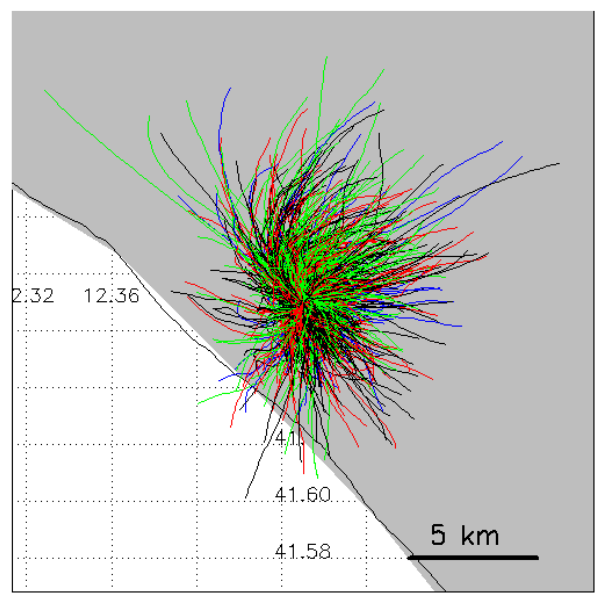

SON

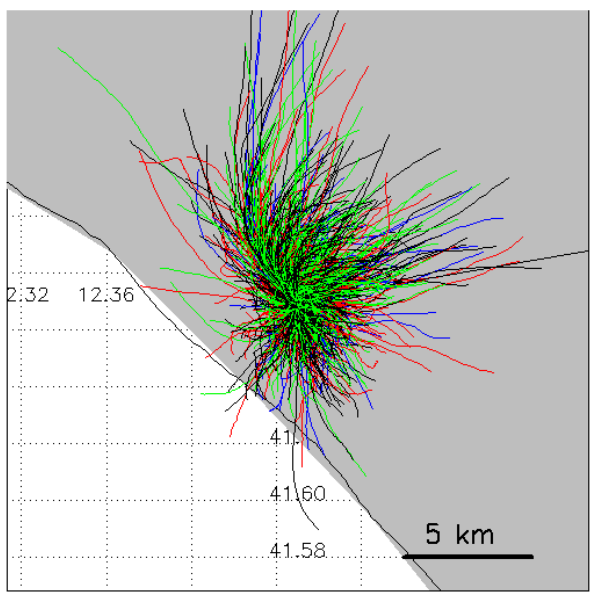

Figure 8. Trajectories of the radiosondes within the lowest $250 \mathrm{hPa}$ in the original sampling dataset (Pratica di Mare station) as a function of the season (a) winter (DJF), (b) spring (MAM), (c) summer (JJA) and (d) autumn (SON). Line colours indicate the launch time in UT (black 00:00, red 06:00, green 12:00, blue 18:00).

Table 4. Number of cases with wind from land (L) and from sea (S) out of total number of soundings with valid wind values at the 2nd level in the sounding, in \%, for each month and each launching time, for the period June 2002-August 2008 available at Pratica di Mare in the original radiosoundings dataset.

\begin{tabular}{cccccccccccccc}
\hline Hour & Jan & Feb & Mar & Apr & May & Jun & Jul & Aug & Sep & Oct & Nov & Dec & Land/ Sea \\
\hline \multirow{2}{*}{$00: 00$} & 40.3 & 34.7 & 25.0 & 17.5 & 15.7 & 11.1 & 15.2 & 13.0 & 25.6 & 30.0 & 30.6 & 41.9 & $\mathrm{~L}$ \\
& 17.9 & 14.3 & 27.5 & 22.2 & 37.8 & 27.8 & 25.0 & 35.1 & 19.0 & 18.0 & 14.5 & 11.0 & $\mathrm{~S}$ \\
\multirow{2}{*}{$06: 00$} & 52.2 & 49.1 & 32.8 & 28.0 & 26.5 & 29.5 & 32.8 & 19.4 & 32.1 & 40.9 & 34.7 & 45.9 & $\mathrm{~L}$ \\
& 12.6 & 13.2 & 17.7 & 14.7 & 16.3 & 11.5 & 17.9 & 19.4 & 14.3 & 18.2 & 20.0 & 7.3 & $\mathrm{~S}$ \\
\multirow{2}{*}{$12: 00$} & 32.3 & 23.7 & 10.1 & 6.8 & 3.9 & 2.8 & 1.4 & 2.0 & 6.1 & 4.8 & 22.6 & 39.8 & $\mathrm{~L}$ \\
& 19.7 & 29.0 & 54.3 & 56.8 & 72.7 & 77.5 & 80.0 & 69.8 & 61.8 & 46.1 & 15.6 & 12.0 & $\mathrm{~S}$ \\
\multirow{2}{*}{$18: 00$} & 28.7 & 11.1 & 2.9 & 5.9 & 8.0 & 2.0 & 1.8 & 4.2 & 7.0 & 00.00 & 2.8 & 29.5 & $\mathrm{~L}$ \\
& 27.5 & 25.9 & 45.7 & 37.3 & 52.0 & 52.0 & 58.9 & 59.6 & 54.9 & 64.7 & 23.9 & 11.5 & $\mathrm{~S}$ \\
\hline
\end{tabular}


We must point out that the detection algorithm is tuned for long-term series; therefore, it should be further optimized for individual cases or for short datasets; for example, by choosing threshold values that are time-dependent and eventually are optimized for each type of datasets - at original vertical or sampled resolution, so that the available information could be better exploited.

\section{Conclusions}

In this study, we propose a new procedure to estimate the height of the ABL using easily available vertically sampled radiosoundings. The purpose is to relate it to the distribution of water vapour in the lowest layers of the atmosphere, which can be retrieved from currently available satellite passive remote sensing observations. We investigated the capability of vertically sampled archived radiosoundings (LOWRES) to describe the seasonal and daily variation of the thermal inversion capping a mixed or residual layer ABL using six-hourly high resolution radiosounding (HIRES) measurements performed at the Italian coastal station of Pratica di Mare. We applied to both datasets a new procedure based on the temperature inversion method, tuned using HIRES radiosoundings.

We also compared the mean seasonal values and the daily cycle of the inversion height from the two datasets: they show a good agreement, although the HIRES data contain a finer structure with respect to the LOWRES profiles.

We applied the new detection algorithms to five additional Mediterranean sites three coastal and two continental. At the three coastal stations we found a lower values of $z_{i}$ during the summer with respect to the rest of the year as found at Pratica di Mare; at the two continental sites, the expected high $z_{i}$ during summer with respect to the rest of the year was observed. Our results are consistent with results found in the literature i.e. coastal stations in the Mediterranean region present an inverse characteristic compared to offshore and continental sites, likely because of the development of sea breeze.

Dissimilarities found in the results, like differences in the average inversion height, as well as other characteristics (e.g. inversion strength) should be further investigated using spatially distributed datasets and numerical modelling. It might be possible to improve the algorithm from the proposed procedure also for individual cases or short datasets by optimizing the estimation method for each type of data. Alternatively changes in the algorithm and/or in the thresholds applied should be tested.

Further work will consist in applying the developed methodology to analyse offshore sounding available from the ASAP database and compare the results obtained for the Mediterranean with results from open Atlantic Ocean for the same latitude range.
Acknowledgements. Italian Meteorological Service kindly provided the high resolution soundings. The authors acknowledge funding from the FP6 Marie Curie Research Network ModObs. MRTN-CT-2005-019369.

Edited by: S.-E. Gryning

Reviewed by: E. Batchvarova and S.-E. Gryning

\section{References}

Batchvarova, E., Gryning, S.-E., Rotach, M. W., and Christen, A.: Comparison of aggregated and measured turbulent fluxes in an urban area, in: Air pollution modeling and its application XVII, 27th NATO/CCMS International Technical Meeting, 25-29 October 2004, Banff, Canada, edited by: Borrego, C. and Norman, A.-L., Springer, 363-370, 2007.

Dayan, U., Heffter, J., and Miller, J.: Seasonal distribution of the boundary layer depths over the Mediterranean basin, in: The Impact of Desert Dust Across the Mediterranean, edited by: Guerzoni, S. and Chester, R., Kluwer, Academic Publishers, 103-112, 1996.

Dayan, U. and Rodnizki, J.: The temporal behaviour of the atmospheric boundary layer in Israel, J. App. Met., 38, 830-836, 1999.

De Tomasi, F. and Perrone, M. R.: PBL and dust layer seasonal evolution by lidar and radiosounding measurements over a peninsular site, Atmos. Res., 80, 86-103, 2006.

Durre, I., Vose, R. S., and Wuertz, D. B.: Overview of the Integrated Global Radiosonde Archive, J. Climate, 19, 1, 53-68, 2006.

Eresmaa, N., Karppinen, A., Joffre, S. M., Rsnen, J., and Talvitie, H.: Mixing height determination by ceilometer, Atmos. Chem. Phys., 6, 1485-1493, 2006,

http://www.atmos-chem-phys.net/6/1485/2006/.

Fetzer, E. J., Teixeira, J., Olsen, E. T., and Fishbein, E. F.: Satellite remote sounding of atmospheric boundary layer temperature inversions over the subtropical eastern Pacific, Geophys. Res. Lett., 31, L17102, doi:10.1029/2004GL020174, 2004.

Gryning, S.-E. and Batchvarova, E.: Marine boundary layer and turbulent fluxes over the Baltic Sea: Measurements and modelling, Bound.-Lay. Meteorol., 103, 29-47, 2002.

Hauser, D., Branger, H., Bouffies-Cloché, S., Despiau, S., Drennan, W., Dupuis, H., Durand, P., Durrieu de Madron, X., Estournel, C., Eymard, L., Flamant, C., Graber, H., Guérin, C., Kahma, K., Lachaud, G., Lefèvre, J.-M., Pelon, J., Pettersson, H., Piguet, B., Queffeulou, P., Tailliez, D., Tournadre, J., and Weill, A.: The FETCH experiment: an overview, J. Geophys. Res., 108(C3), 8053, doi:10.1029/2001JC001202, 2003.

Heffter, J. L.: Transport Layer Depth Calculations, Second Joint Conference on Applications of Air Pollution Meteorology, New Orleans, LA, 1980.

Hyvarinen, O. and Rantamaki, M.: Possibilities of operational detection of temperature inversions with satellite remote sensing, Proceedings of EUMETSAT Meteorological Conference, Prague, Czech Republic, 31 May-4 June, P41, ISBN 92-9110066-8, ISSN 1011-3932, 338-344, 2004.

Joffre, S., Kangas, M., Heikinheimo, M., and Kitaigorodskii, A.: Variability of the stable and unstable atmospheric boundary-layer height and its scales over a boreal forest, B. L. Met., 99, 429-450, 2001. 
Johansson, C., Hennemuth, B., Bösenberg, B., Linné, H., and Smedman, A.-S.: Double-layer structure over the Baltic Sea; Climatology, Case Study and Simulation, B. L. Met., 114, 389-412, 2005.

Liu, Y. and Key, J. R.: Detection and analysis of low-level temperature inversions with MODIS, J. Atm. Ocean. Techn., 20, 17231737, 2003.

Liu, Y., Key, J. R., Schwiger, A., and Francis, J.: Characteristics of Satellite-Derived Clear-Sky Atmospheric Temperature Inversion Strength in the Arctic, 1980-96, J. Climate, 4902-4913, 2006.

Martano, P.: An algorithm for the calculation of the time dependent mixing height in coastal site, J. Appl. Meteorol., 41, 351-354, 2002.

Seibert, P., Beyrich, F., Gryning, S. E., Joffre, S., Rasmussen, A., and Tercier, P.: Review and intercomparison of operational methods for the determination of the mixing height, Atmos. Environ., 34, 1001-1027, 2000.
Sempreviva, A. M. and Gryning, S. E.: Mixing height over water and it's role on the correlation between temperature and humidity fluctuations in the unstable surface layer, B. L. Met., 97, 273291, 2000.

Sicard, M., Pérez, C., Rocadenbosch, F., Baldasano, J., and GarcíaVizcaino, D.: Mixed-Layer Depth Determination in the Barcelona Coastal Area From Regular Lidar Measurements: Methods, Results and Limitations, B. L. Met., 119, 135-157, 2006.

Smedman, A.-S., Högström, U., Hunt, J. C. R., and Sahlee, E.: Heat/mass transfer in the slightly unstable atmospheric surface layer, Q. J. Met. Soc., 133, 37-51, 2007.

Webster, P. J. and Lukas, R.: TOGA COARE: The Coupled OceanAtmosphere Response Experiment, B. Am. Meteorol. Soc., 73, 1377-1416, 1992 